\title{
ULTRASONIC ATTENUATION IN ALLOYS
}

\author{
S.K. KoR AND R.K. SINGII \\ Department of Physics, University of Allahabad, Allahabad-211 002, India \\ (Received July 9, 1992; in final form Oclober 30, 1992)

\begin{abstract}
Ultrasonic attenuation was evaluated in metallic alloys, $\mathrm{Ni}_{x} \mathrm{Cu}_{1-x}(x=$ $1.00,0.70,0.60,0.45$ and 0$)$ due to phonon-phonon (p-p) interaction and thermoelastic loss in a wide temperature region along $\langle 110\rangle$ crystallographic direction for longitudinal and shear waves. Ultrasonic Grüneisen parameters, nonlinearity constants and ultrasonic attenuation due to $\mathrm{p}-\mathrm{p}$ interaction and thermoelastic loss were determined from $50 \mathrm{~K}$ to $500 \mathrm{~K}$ using the Born-Mayer and electrostatic potentials. The results were compared with a vailable experimental results.
\end{abstract}

PACS numbers: 62.20.Dc, 62.65.+k

\section{Introduction}

Ultrasonic attenuation studies have been recently made in metals [1-3], semiconductors $[4,5]$ and dielectric materials $[6,7]$ as a function of temperature, frequency and direction of propagation. From all these studies it is well established that at higher temperatures, i.e. $50 \mathrm{~K}$ and above, phonon-phonon interaction is the dominant cause of the ultrasonic attenuation in all types of solids. In metals, due to higher thermal conductivity, a part of total ultrasonic attenuation arises due to thermoelastic loss, too. In the present investigation we made theoretical evaluation of the ultrasonic absorption coefficient (upon frequency square) in $\mathrm{Ni}$, $\mathrm{Ni}_{70} \mathrm{Cu}_{30}, \mathrm{Ni}_{60} \mathrm{Cu}_{40}, \mathrm{Ni}_{45} \mathrm{Cu}_{55}$ and $\mathrm{Cu}$ as a function of temperature along $\langle 110\rangle$ direction for longitudinal and shear waves, and shear waves polarized along $\langle 001\rangle$ and $\langle 1 \overline{1} 0\rangle$ directions. A model potential consisting of electrostatic and Born-Mayer [8] type potentials was used to evaluate second- and third-order elastic constants (SOEC and TOEC) of these alloys and metals, using nearest-neighbour distance and hardness parameter of the substance as input data.

\section{Theory}

\subsection{Theory of elastic constants}

The potential used for evaluation of SOEC and TOEC is

$\phi=\phi_{\mathrm{c}}+\phi_{\mathrm{r}}$ 
TABLE I

Expressions for SOEC and TOEC at absolute zero.

\begin{aligned} \hline \hline$C_{11}^{0}= & -0.87378\left(e^{2} / r_{0}^{4}\right)+\left(1 / \rho r_{0}\right)\left(1 / r_{0}+1 / \rho\right) \phi\left(r_{0}\right) \\ & +\left(2 / \rho r_{0}\right)\left(\sqrt{2} / 2 r_{0}+1 / \rho\right) \phi\left(\sqrt{2} r_{0}\right) \\ C_{12}^{0}= & C_{44}^{0}=0.347775(3 / 2)\left(e^{2} / r_{0}^{4}\right)+\left(1 / \rho r_{0}\right)\left(\sqrt{2} / 2 r_{0}+1 / \rho\right) \phi\left(\sqrt{2} r_{0}\right) \\ C_{111}^{0}= & 10.2639\left(e^{2} / r_{0}^{4}\right)-(1 / \rho)\left(3 / r_{0}^{2}+3 / \rho r_{0}+1 / \rho^{2}\right) \phi\left(r_{0}\right) \\ & -(1 / 2 \rho)\left(3 \sqrt{2} / r_{0}^{2}+6 / \rho r_{0}+2 \sqrt{2} / \rho^{2}\right) \phi\left(\sqrt{2} r_{0}\right) \\ C_{112}^{0}= & C_{166}^{0}=1.209625\left(e^{2} / r_{0}^{4}\right)+(1 / 4 \rho)\left(3 \sqrt{2} / r_{0}^{2}+6 / \rho r_{0}+2 \sqrt{2} / \rho^{2}\right) \phi\left(\sqrt{2} r_{0}\right) \\ C_{123}^{0}= & C_{144}^{0}=C_{456}^{0}=0.678375\left(e^{2} / r_{0}^{4}\right)\end{aligned}$

TABLE II

Vibrational energy contribution to elastic constants.

\begin{tabular}{l}
\hline$a_{11}^{\text {vib }}=G_{0}\left(G_{2}-G_{1}^{2} / 6\right) ; a_{12}^{\text {vib }}=G_{0}\left(G_{1,1}-G_{1}^{2} / 6\right) ; \quad a_{44}^{\text {vib }}=G_{0} G_{1,1} / 4$ \\
$a_{111}^{\text {vib }}=G_{0}\left(G_{3}-G_{2} G_{1} / 2+G_{1}^{3} / 18\right)$ \\
$a_{112}^{\text {vib }}=G_{0}\left(G_{2,1}-G_{1,1} G_{1} / 3-G_{2} G_{1} / 6+G_{1}^{3} / 18\right)$ \\
$a_{123}^{\text {vib }}=G_{0}\left(G_{1,1,1}-G_{1,1} G_{1} / 2+G_{1}^{3} / 18\right)$ \\
$a_{144}^{\text {vib }}=G_{0}\left(G_{1,1,1}-G_{1,1} G_{1} / 2\right)$ \\
$a_{166}^{\text {vib }}=G_{0}\left(G_{1,1,1}-G_{1,1} / 2+G_{2,1}\right)$ \\
$a_{456}^{\text {vib }}=G_{0} G_{1,1,1} ; \quad G_{1,1,1}=0, G_{0}=k / 8 r_{0}^{3}$
\end{tabular}

TABLE III

Expressions for various $G_{n}$.

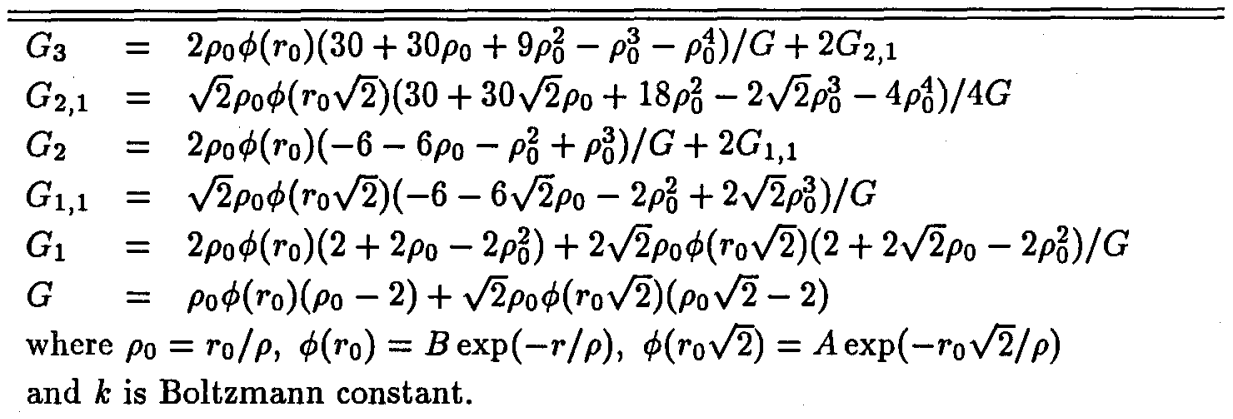

where $\phi_{\mathrm{c}}$ is electrostatic potential and $\phi_{\mathrm{r}}$ is repulsive potential given as

$$
\phi_{\mathrm{c}}=z^{2} e^{2} / r \text { and } \phi_{\mathrm{r}}=A \exp (-r / \rho) \text {. }
$$

Following Brugger's [9] definition of elastic constants, and starting from nearest-neighbour distance and hardness parameter of the substance and taking interactions effective up to second nearest-neighbour distance, SOEC and TOEC 
were obtained at absolute zero as shown in Table I. According to the lattice dynamics developed by Leibfried et al. [10], lattice energy changes with temperature, hence adding vibrational energy contribution to elastic constants at absolute zero one gets $C_{i j}$ and $C_{i j k}$ (SOEC and TOEC) at required temperature as

$$
\begin{aligned}
& C_{i j}(T)=C_{i j}^{0}+a_{i j} T, \\
& C_{i j k}(T)=C_{i j k}^{0}+a_{i j k} T,
\end{aligned}
$$

where superscript 0 has been used to denote SOEC and TOEC at absolute zero. $a_{i j}$ and $a_{i j k}$ are defined as

$$
\begin{aligned}
& a_{i j}=l_{1} k\left(\partial C_{i j} / \partial r\right)_{r=r_{0}}+a_{i j}^{\mathrm{vib}}, \\
& a_{i j k}=l_{1} k\left(\partial C_{i j k} / \partial r\right)_{r=r_{0}}+a_{i j k}^{\mathrm{vib}},
\end{aligned}
$$

where $a_{i j}^{\text {vib }}$ and $a_{i j k}^{\text {vib }}$ are various constants as given in Table II, various $G_{n}$ appearing in Table II have been given in Table III. $l_{1}$ is a function of nearest-neighbour distance and hardness parameter and for face centred cubic crystals given as

$$
l_{1}=-\rho\left[\left(2+2 \rho_{0}-\rho_{0}^{2}\right) \phi\left(r_{0}\right)+2 \sqrt{2}\left(1+2 \rho_{0}-\rho\right) \phi\left(r_{0} \sqrt{2}\right)\right] / l_{2},
$$

where

$$
\begin{aligned}
l_{2}= & 2\left[\left(\rho_{0}-2\right) \phi\left(r_{0}\right)+2\left(\rho_{0}-\sqrt{2}\right) \phi\left(r_{0} \sqrt{2}\right)\right] \\
& \times\left[\left(\rho_{0}-2\right) \phi\left(r_{0}\right)+4\left(\rho_{0}-\sqrt{2}\right) \phi\left(r_{0} \sqrt{2}\right)\right] .
\end{aligned}
$$

\subsection{Ultrasonic attenuation due to phonon-phonon interaction}

Ultrasonic attenuation due to phonon-viscosity mechanism ( $\mathrm{p}-\mathrm{p}$ interaction) [11] is given as

$$
\alpha=\frac{\omega^{2} \tau_{\mathrm{th}} E_{0} \Gamma}{3 d v^{3}\left(1+\omega^{2} \tau_{\mathrm{th}}^{2}\right)} .
$$

The above expression in Akhiezer regime [12] $\left(\tau_{\mathrm{th}} \omega \ll 1\right)$ reduces to

$$
\begin{aligned}
& \left(\alpha / f^{2}\right)_{1}=\frac{(2 \pi)^{2} \Gamma_{\mathrm{l}} E_{0} \tau_{\mathrm{th}}}{3 d v_{\mathrm{l}}^{3}}, \\
& \left(\alpha / f^{2}\right)_{\mathbf{s}}=\frac{2 \pi^{2} \Gamma_{\mathrm{s}} E_{0} \tau_{\mathrm{th}}}{3 d v_{\mathrm{s}}^{3}}
\end{aligned}
$$

for longitudinal and shear waves respectively. $\Gamma$ is nonlinearity coupling constant (subscripts $l$ and $\mathbf{s}$ denote longitudinal and shear waves respectively); $E_{0}$ is energy density of the crystal, $d$ is density, $v_{\mathrm{l}}$ being longitudinal wave velocity and $v_{\mathrm{s}}$ shear wave velocity and $\tau_{\text {th }}$ is thermal relaxation time given as

$$
(1 / 2) \tau_{n}=\tau_{\mathrm{th}}=\tau_{\mathrm{s}}=3 k / C_{v}\langle v\rangle^{2}
$$

where $k$ is thermal conductivity, $C_{v}$ is specific heat per unit volume and $\langle v\rangle$ is the Debye average velocity obtained as

$$
\langle v\rangle=\left[(1 / 3)\left(2 / v_{\mathrm{s}}^{3}+1 / v_{1}^{3}\right)\right]^{-1 / 3} .
$$


$\Gamma$ is obtained as

$$
\Gamma=9\left\langle\gamma_{i}^{j}{ }^{2}\right\rangle-\frac{3\left\langle\gamma_{i}^{j}\right\rangle^{2} C_{v} T}{E_{0}},
$$

where $\left\langle\gamma_{i}^{j}\right\rangle$ and $\left\langle\gamma_{i}^{j}\right\rangle$ are average and square average Grüneisen numbers [11].

Ultrasonic attenuation due to thermoelastic loss $\left(\alpha / f^{2}\right)_{\text {th }}$ is obtained as

$$
\left(\alpha / f^{2}\right)_{\mathrm{th}}=\frac{2 \pi^{2} k T\left(\gamma_{i}^{j}\right)^{2}}{d v_{1}^{5}}
$$

For shear waves $\left\langle\gamma_{i}^{j}\right\rangle$ becomes zero, hence there is no thermoelastic loss due to propagation of shear waves.

\section{Evaluation}

Taking nearest-neighbour distance [13] $\left(\mathrm{Ni}=2.489, \mathrm{Ni}_{70} \mathrm{Cu}_{30}=2.516\right.$, $\mathrm{Ni}_{60} \mathrm{Cu}_{40}=2.516, \mathrm{Ni}_{45} \mathrm{Cu}_{55}=2.526$ and $\mathrm{Cu}=2.558$, all in $\AA$ ) and hardness parameter [14] of the substances, SOEC and TOEC were obtained at different temperatures using the theory developed above. SOEC and TOEC thus obtained were used to obtain $\left\langle\gamma_{i}^{j}\right\rangle$ and $\left\langle\gamma_{i}^{j}{ }^{2}\right\rangle$ along $\langle 110\rangle$ direction for longitudinal wave over 39 pure modes and for shear waves polarized along $\langle 001\rangle$ direction over 20 modes and for polarization along $\langle 1 \overline{1} 0\rangle$ over 18 modes using Mason's Grüneisen table $[11,15] . C_{\mathrm{V}}$ and $E_{0}$ have been obtained [16] as a function of $\Theta_{\mathrm{D}} / T$, at different temperatures $\left(\Theta_{D}\right.$ is the Debye temperature) as shown in Table IV.

\section{TABLE IV}

Specific heat per unit volume, $C_{\mathrm{V}}\left(10^{7} \mathrm{erg} / \mathrm{cm}^{3} \mathrm{~K}\right)$ and thermal energy density, $E_{0}\left(10^{9} \mathrm{erg} / \mathrm{cm}^{3}\right)$ at different temperatures for different $\mathrm{NiCu}$ alloys.

\begin{tabular}{c|l|r|r|r|r|r|r}
\hline \hline $\begin{array}{c}\text { \% of } \mathrm{Cu} \\
\text { in } \mathrm{NiCu}\end{array}$ & & \multicolumn{6}{|c}{ Temperature [K] } \\
\cline { 3 - 8 } 0 & $C_{\mathrm{V}}$ & 0.38 & 1.64 & 3.06 & 3.40 & 3.55 & 3.62 \\
& $E_{0}$ & 0.03 & 0.56 & 3.00 & 6.22 & 9.89 & 13.25 \\
30 & $C_{\mathrm{V}}$ & 0.47 & 1.77 & 3.00 & 3.49 & 3.54 & 3.54 \\
& $E_{0}$ & 0.03 & 0.62 & 3.25 & 6.35 & 9.77 & 13.76 \\
40 & $C_{\mathrm{V}}$ & 0.49 & 1.82 & 3.01 & 3.36 & 3.46 & 3.52 \\
& $E_{0}$ & 0.03 & 0.65 & 3.19 & 6.29 & 9.97 & 14.09 \\
55 & $C_{\mathrm{V}}$ & 0.53 & 1.88 & 3.02 & 3.34 & 3.45 & 3.49 \\
& $E_{0}$ & 0.06 & 0.69 & 3.26 & 6.47 & 9.83 & 14.10 \\
100 & $C_{\mathrm{V}}$ & 0.70 & 2.09 & 3.04 & 3.29 & 3.37 & 3.41 \\
& $E_{0}$ & 0.25 & 0.82 & 3.25 & 6.69 & 10.00 & 12.81
\end{tabular}

Nonlinearity constants $\left(\Gamma_{1}\right.$ and $\Gamma_{\mathrm{s}}$ ) were obtained using Eq. (12). Thermal relaxation time was obtained taking thermal conductivity [16-18] with the help 
TABLE V

Thermal relaxation time $\left(10^{-11} \mathrm{~s}\right)$ and nonlinearity constant ratio at different temperatures for different $\mathrm{NiCu}$ alloys.

\begin{tabular}{c|l|r|r|r|r|r|r}
\hline \hline \% of Cu & & \multicolumn{6}{|c}{ Temperature [K] } \\
\cline { 3 - 8 } in NiCu & & 50 & 100 & 200 & 300 & 400 & 500 \\
\hline 0 & $\tau_{\text {th }}$ & 5.30 & 2.08 & 0.56 & 0.57 & 0.50 & 0.46 \\
& $\Gamma_{\mathrm{l}} / \Gamma_{\mathrm{s}}^{*}$ & 1.16 & 1.42 & 1.49 & 1.51 & 1.55 & 1.54 \\
& $\Gamma_{\mathrm{l}} / \Gamma_{\mathrm{s}}^{* *}$ & 0.28 & 0.36 & 0.39 & 0.38 & 0.37 & 0.37 \\
30 & $\tau_{\text {th }}$ & 6.24 & 5.11 & 2.406 & 2.07 & 2.09 & 2.07 \\
& $\Gamma_{\mathrm{l}} / \Gamma_{\mathrm{s}}^{*}$ & 0.75 & 1.15 & 1.50 & 1.79 & 1.84 & 2.14 \\
& $\Gamma_{\mathrm{l}} / \Gamma_{\mathrm{s}}^{* *}$ & 0.31 & 0.44 & 0.57 & 0.70 & 0.73 & 0.86 \\
40 & $\tau_{\text {th }}$ & 5.32 & 4.52 & 2.20 & 1.98 & 1.87 & 1.87 \\
& $\Gamma_{\mathrm{l}} / \Gamma_{\mathrm{s}}^{*}$ & 0.90 & 1.22 & 1.55 & 1.77 & 1.94 & 21.14 \\
& $\Gamma_{\mathrm{l}} / \Gamma_{\mathrm{s}}^{* *}$ & 0.35 & 0.47 & 0.60 & 0.68 & 0.77 & 0.86 \\
55 & $\tau_{\text {th }}$ & 5.86 & 3.90 & 1.82 & 1.69 & 1.59 & 1.57 \\
& $\Gamma_{\mathrm{l}} / \Gamma_{\mathrm{s}}^{*}$ & 0.98 & 1.22 & 1.58 & 1.77 & 1.90 & 2.14 \\
& $\Gamma_{\mathrm{l}} / \Gamma_{\mathrm{s}}^{* *}$ & 0.31 & 0.46 & 0.60 & 0.68 & 0.74 & 0.85 \\
100 & $\tau_{\text {th }}$ & 7.85 & 5.56 & 3.22 & 2.88 & 0.68 & 0.63 \\
& $\Gamma_{\mathrm{l}} / \Gamma_{\mathrm{s}}^{*}$ & 1.04 & 1.20 & 1.34 & 1.38 & 1.37 & 1.16 \\
& $\Gamma_{\mathrm{l}} / \Gamma_{\mathrm{s}}^{* *}$ & 0.42 & 0.46 & 0.52 & 0.54 & 0.54 & 0.49
\end{tabular}

* For shear wave polarised along $\langle 001\rangle$ direction.

** For shear wave polarised along $\langle 1 \overline{1} 0\rangle$ direction.

of Eq. (10). Thermal relaxation time and nonlinearity constant ratio at different temperatures have been shown in Table V. Ultrasonic attenuation due to phonon-phonon interaction and thermoelastic loss was obtained at different temperatures using Eqs. (8), (9), and (13).

\section{Results and discussion}

Values of nonlinearity constant ratio $\Gamma_{1} / \Gamma_{\mathrm{s}}$ at different tempcratures have been shown in Table $\mathrm{V}$ for different atomic concentrations of $\mathrm{Cu}$ in $\mathrm{Ni}$. The ratio lies between 1 to 2 for shear wave polarized along the 001$\rangle$ direction and is less than 1 for the polarization along the $\langle 1 \overline{1} 0\rangle$ direction, like other substances [5]. Thermal relaxation time $\boldsymbol{r}_{\mathrm{lh}}$ (Table $\mathrm{V}$ ) first increases with temperature and at higher temperatures it attains the saturation value as in the case of other metals [1]. From the magnitude of thermal relaxation time one can check the validity of the condition $\omega \tau_{\mathrm{th}} \ll 1$ in the ultrasonic frequency range. $\left(\alpha / f^{2}\right)$ at different temperatures has been shown for longitudinal and shear waves in Figs. 1-5. From the 


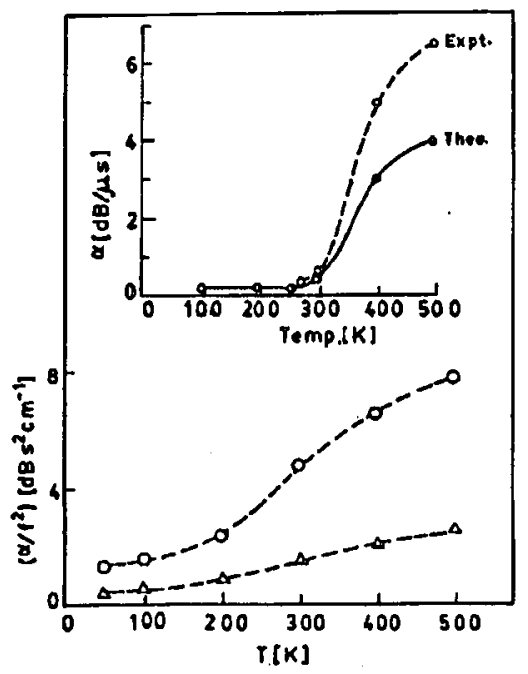

Fig. 1. Ultrasonic attenuation due to $\mathrm{p}-\mathrm{p}$ interaction in $\mathrm{Ni}$ for shear wave (-0 - - in $\left.10^{-17} \mathrm{~dB} \mathrm{~s}^{2} \mathrm{~cm}^{-1}\right)$ polarised along $\langle 001\rangle$ direction and for shear wave $(--\Delta--$ in $10^{-16} \mathrm{~dB} \mathrm{~s}^{2} \mathrm{~cm}^{-1}$ ) polarised along $\langle 110\rangle$ direction. Inset: experimental and theoretical values of ultrasonic attenuation for longitudinal wave in $\mathrm{Ni}$.
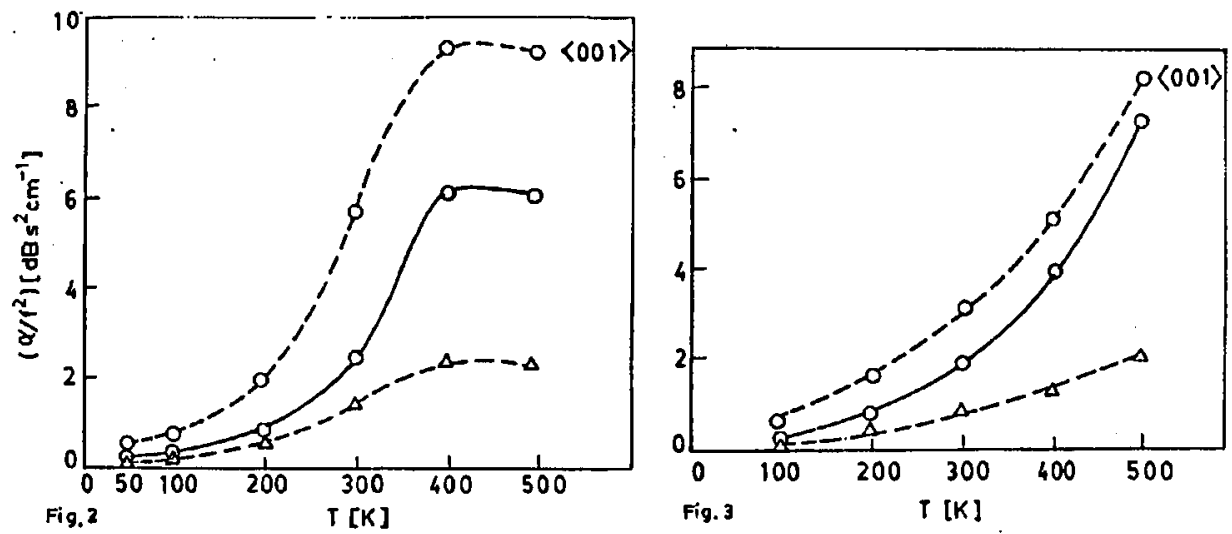

Fig. 2. Ultrasonic attenuation due to $\mathrm{p}-\mathrm{p}$ interaction in $\mathrm{Ni}_{70} \mathrm{Cu}_{30}$ for longitudinal wave (一o- in $10^{-16} \mathrm{~dB} \mathrm{~s}^{2} \mathrm{~cm}^{-1}$ ), for shear wave (- - -- in $10^{-16} \mathrm{~dB} \mathrm{~s}^{2} \mathrm{~cm}^{-1}$ ) polarised along $\langle 001\rangle$ direction and for shear wave $\left(--\Delta--\right.$ in $\left.10^{-15} \mathrm{~dB} \mathrm{~s}^{2} \mathrm{~cm}^{-1}\right)$ polarised along $\langle 1 \overline{1} 0\rangle$ direction.

Fig. 3. Ultrasonic attenuation due to $\mathrm{p}-\mathrm{p}$ interaction in $\mathrm{Ni}_{60} \mathrm{Cu}_{40}$ for longitudinal wave (-o- in $\left.10^{-16} \mathrm{~dB} \mathrm{~s}^{2} \mathrm{~cm}^{-1}\right)$, for shear wave $\left(--0--\right.$ in $10^{-16} \mathrm{~dB} \mathrm{~s}^{2} \mathrm{~cm}^{-1}$ ) polarised along $\langle 001\rangle$ direction and for shear wave $\left(--\Delta--\right.$ in $\left.10^{-16} \cdot \mathrm{dB} \mathrm{s}^{2} \mathrm{~cm}^{-1}\right)$ polarised along $\langle 1 \overline{1} 0\rangle$ direction. 

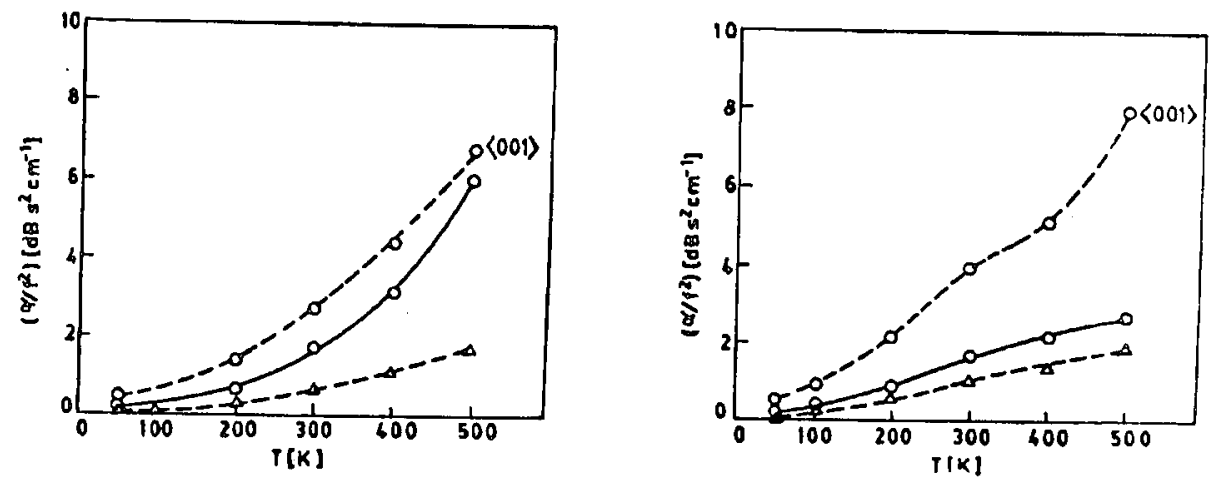

Fig. 4. Ultrasonic altenuation due to $\mathrm{p}-\mathrm{p}$ interaction in $\mathrm{Ni}_{45} \mathrm{Cu}_{55}$ for longitudinal wave (-o- in $10^{-16} \mathrm{~dB} \mathrm{~s}^{2} \mathrm{~cm}^{-1}$ ), for shear wave (-- -- in $10^{-16} \mathrm{~dB} \mathrm{~s}^{2} \mathrm{~cm}^{-1}$ ) polarised along $\langle 001\rangle$ direction and for shear wave $\left(--\Delta--\right.$ in $\left.10^{-15} \mathrm{~dB} \mathrm{~s}^{2} \mathrm{~cm}^{-1}\right)$ polarised along $\langle 1 \overline{1} 0\rangle$ direction.

Fig. 5. UItrasonic attenuation due to $\mathrm{p}-\mathrm{p}$ interaction in $\mathrm{Cu}$ for longitudinal wave (一o- in $10^{-16} \mathrm{~dB} \mathrm{~s}^{2} \mathrm{~cm}^{-1}$ ), for shear wave (- - o- - in $10^{-16} \mathrm{~dB} \mathrm{~s}^{2} \mathrm{~cm}^{-1}$ ) polariscd along $\langle 001\rangle$ direction and for shear wave $\left(--\Delta--\right.$ in $\left.10^{-15} \mathrm{~dB}^{2} \mathrm{~cm}^{-1}\right)$ polarised along $\langle 1 \overrightarrow{1} 0\rangle$ direction.

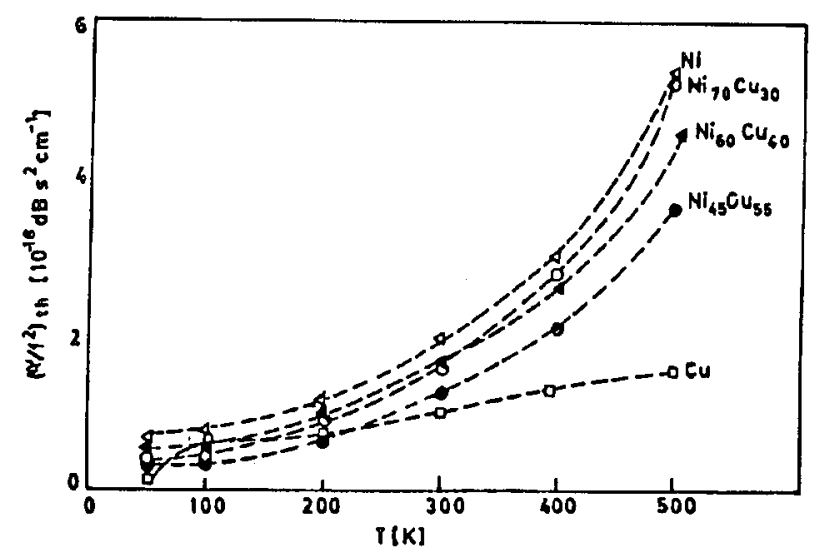

Fig. 6. Ultrasonic attenuation due to thermoelastic loss.

figures it is evident that the ultrasonic attenuation increases with temperature due to phonon-phonon interaction for all the alloys and metals studied. Experimental results are available for $\mathrm{Ni}$ along $\langle 110\rangle$ direction for longitudinal wave at different temperatures at $15 \mathrm{MHz}$. We compared our results with the observed valucs of Basu [19] as shown in Fig. 1. From the figure one can see that the variation of the ultrasonic attenuation is the same as observed by Basu at lower temperaturcs. 
Though no experimental results have been available for these alloys yet, we expect our values to be correct, seeing the agreement between theoretical and experimental values for $\mathrm{Ni}$. The magnitude of the attenuation in the case of these metallic alloys is of the same order as observed in metals [1]. Ultrasonic attenuation due to thermoelastic loss has been shown in Fig. 6 at different temperatures. $\left(\alpha / f^{2}\right)_{\mathrm{th}}$ for alloys and metals studied increases with temperature like in metals [1].

Thus, it can be concluded that the metallic alloys behave more or less like metals as far as their ultrasonic attenuation properties are concerned.

\section{References}

[1] S.K. Kor, Kailash, Indian J. Pure Appl. Phys. 24, 179 (1986).

[2] S.K. Kor, Kailash, K. Shanker, P. Mehrotra, J. Phys. Soc. Jpn. 7, 2428 (1987).

[3] S.K. Kor, R.K. Singh, Acustica, submitted for publication.

[4] S.K. Kor, Kailash, J. Phys. Soc. Jpn. 55, 2232 (1986).

[5] M.O. Manasreh, D.O. Pederson, Solid Slate Ion. Diffus. React. 15, 65 (1985).

[6] S.K. Kor, R.R. Yadav, Kailash, J. Phys. Soc. Jpn. 55, 287 (1986).

[7] S.K. Kor, R.K. Singh, Acta Phys. Pol. A 80, 805 (1991).

[8] M. Born, J. Mayer, Z. Phys. 75, 1 (1932).

[9] K. Brugger, Phys. Rev. A 133, 1611 (1964).

[10] G. Leibfried, W. Ludwig, in: Solid State Physics, Vol. 12, Eds. F. Seitz, D. Turnbull, Academic Press, New York 1961, p. 276.

[11] W.P. Mason, Physical Acoustics, Vol. 3, Academic Press, New York 1965.

[12] A. Akhiezer, J. Phys. (USSR) 1, 277 (1939).

[13] C. Kittel, Introduction to Solid State Physics, Wiley, New York 1981.

[14] M.P. Tosi, in: Solid State Physics, Vol. 16, Eds. F. Seitz, D. Turnbull, Academic Press, New York 1964, p. 1.

[15] W.P. Mason, R. Rosenberg, J. Acoust. Soc. Am. 45, 47 (1969).

[16] American Institute of Physics Handbook, Ed. D.E. Gray, McGraw-IIill, New York 1972.

[17] C.Y. No, M.W. Ackeman, K.Y. Wus, C. Gel, T.N. Haril, J. Phys. Chem. Ref. Dala 7, 957 (1978).

[18] CRC Handbook of Chemistry and Physics, Ed. R.C. Weast, CRC Press, Florida 1981.

[19] A. Basu, J. Appl. Phys. 29, 961 (1974). 